\title{
The use of ternary cements to reduce the environmental impact of concrete
}

\author{
Kim-Séang Lauch ${ }^{\mathrm{a}^{*}}$, Vinciane Dieryck ${ }^{\mathrm{a}}$, Valérie Pollet ${ }^{\mathrm{a}}$ \\ ${ }^{a}$ Belgian Building Research Institute, Av. Pierre Holoffe 21, 1342 Limelette, Belgium
}

Received: 12 October 2016 / Accepted: 16 December 2016 / Published online: 20 December 2016

(C) The Author(s) 2016. This article is published with open access.

\begin{abstract}
In the current context of climate change, reducing the greenhouse gas emissions is one of the greatest challenges of our society. As concrete is the second most used material in the world after water, its environmental impact is significant, especially because of the production of cement. Clinker substitution is according to the International Energy Agency and the World Business Council for Sustainable Development one of the four main reductions levers for the cement industry. Unlike Carbon Capture and Storage technology, replacing clinker with by-products such as fly ash and blastfurnace slag is technically feasible and applicable today. The use of blended cements is nowadays more and more commonly widespread. Ternary cements is particularly advantageous to benefit the synergetic action of two substitutes such as fly ash and limestone filler. Cement standard EN $197-1$ is evolving towards more ternary binders but their impact on concrete properties are not thoroughly investigated yet. This paper presents some effects of newly developed ternary cements on concrete. The use of composite cements is a compelling solution to reduce the environmental impact of concrete but it is necessary to always assess their suitability in concrete.
\end{abstract}

Keywords: Blended cement; Limestone filler; Blast furnace slag; Fly ash; Sustainability

\section{Introduction}

The European Commission established a Roadmap for moving to a competitive low-carbon economy in 2050. By that time, the European Union should cut greenhouse gas emissions to $80 \%$ below 1990 levels. To reach this goal, the EU must make continued progress towards a low-carbon society [1].

The construction industry is one of the main sectors responsible for Europe's emissions. Concrete is the most used material in the world. About 10 billion tons of concrete are produced each year [2] and the demand is expected to increase even further, especially in the developing countries. The production of this massive quantity leads thus to a huge impact on the environment, mainly because of the production of cement. Because the production of one ton of Portland cement emits on average 0.87 tons of $\mathrm{CO}_{2}$ [3], the cement industry is responsible for about $5 \%$ of current global man-made $\mathrm{CO}_{2}$ emissions [4]. That is why the International Energy Agency (IEA) and the World Business Council for Sustainable Development (WBCSD) established a Cement Technology Roadmap 2009 [4]. Among thermal and electric efficiency, alternative fuel use and carbon capture and storage (CCS), clinker substitution is one of the four main reductions levers for the cement industry.

Replacing clinker with supplementary cementitious materials (SCMs) is a compelling solution, which is technically feasible and applicable today (unlike the CSS technology) to reduce the environmental impact of concrete. Clinker is mostly substituted with by-products such as ground granulated blast furnace slag (from the iron or steel industry) and fly ash (from coal-fired power stations). Other substitutes include: natural pozzolans (e.g. volcanic ash), rice husk ash, silica fume, artificial pozzolans (e.g. calcined clay) and limestone. It should be noted that there exists a wide regional difference. While in most of European countries clinker substitutes are directly blended in cement, in the US and in Canada, they are typically added at the concrete level [4].

The development of binary and ternary cements has rapidly increased these past decades. The share of production of non-CEM I cements in the EU, as a percentage of all EU cement production, has risen by $13.1 \%$ to $72.5 \%$ between 1994 and 2004 [5]. The cement producers in Belgium (and in the Netherlands) are the pioneers in Europe in the development of cement with clinker substitutes. In 2006, the substitution rate of clinker came already to about 30\%, which was one of the highest replacement level. It has still

* Corresponding author: Kim-Séang Lauch, kim-seang.lauch@bbri.be, Tel: +32 26557711 
been increasing along the year and reached nearly $38 \%$ in 2015 [6].

The trend is to increase the replacement levels of clinker and to optimise different combinations of cementitious materials [7]. Limestone filler is readily available whereas there is uncertainty around the future availability of slag and fly ash. As Snellings highlighted [8], supply concerns about conventional high-quality SCMs are raising and alternative sources of SCMs, such as calcined clays, are more and more researched nowadays [9].

Slag and fly ash are characterized by a pozzolanic reactivity which contributes to the long-term strength, while a small dosage of limestone filler could have a beneficial effect on the early age properties of concrete $[10,11]$. Ternary mixes are particularly interesting by combining these antagonist properties of limestone filler at early age and of slag or fly ash at later age. Several studies investigated their synergetic action [7, 10-14].

The European standard EN 197-1 (2011) gives 27 types of common cements, mainly binary. Currently under revision, this standard would add new types of ternary cements, with a clinker content from $35 \%$ to $64 \%$ and a limestone filler content up to $20 \%$, which shows a trend to include more limestone filler in composite binders. The standard includes requirements for the constituents as well as mechanical (early and standard strength), physical (initial setting time and soundness), chemical and durability requirements for the cements for use in concrete. Questions arise as to whether these requirements and those for concrete compositions from European standard EN 206 (2014) are sufficient to use these cements in all concrete applications.

The aim of this study is to evaluate the performance of concrete made with newly developed ternary cement combining Portland cement (OPC), slag (S) or fly ash (FA) and a high amount of limestone filler (L). As indicated by Mueller [15], one of the approaches to a sustainable use of concrete is to reduce the environmental impact of concrete while maintaining at least an equal performance and service life.

The present paper is part of a wide research program on assessing the mechanical and durability performance of concrete made with these composite cements, in comparison with reference concretes made with industrial cements which satisfy the requirements of standard EN 1971. This is in line with one of the recommendations of the IEA and WBCSD. They recommend promoting exchanges in experiences on substitution, concrete standards and longterm concrete performance of new cements [4]. This is also in line with the recent technical report CEN/TR 16912 concerning guidelines for a procedure to support the European standardization of cements.

The main effects of these ternary cements on concrete are presented. The detailed results are presented in other papers for the fresh and mechanical properties [16] and for the durability performance [17].

\section{New ternary cements}

In Belgium, there is nowadays a shortage of blast furnace slag (S) following a decrease in activity of the steel industry. In order to be less dependent on the producers of slag and to vary the sources of raw materials, fly ash (FA) has also been considered. Limestone filler $(L)$ is abundantly available. The production in Wallonia (Belgium) is estimated at 1 million tons each year (Piérard \& Michel, 2008).

This study focuses on slag-based ternary cements OPC-S-L in a first series and on fly ash-based ternary cements OPC-FA-L in a second series. The composite cements were prepared by mixing CEM I 52.5 R HES with these SCMs. Gypsum had been added with a concentration to obtain a total sulfate content of $3 \%$. The different proportions of these studied ternary mixes, named CEM 1 to CEM 12, are illustrated in ternary diagrams in Fig. 1 and Fig. 2: OPC is from 35\% to 75\%, slag and fly ash from $10 \%$ to $30 \%$, and limestone filler from $5 \%$ to 45\%. In series 1, cements CEM I 52.5 R HES, CEM II/B-M (L-S) $32.5 \mathrm{R}$ and CEM III/A 42.5 N LA were used as reference cements. In series 2, cements CEM I 52.5 R HES, CEM II/B-M (LL-S-V) $32.5 \mathrm{~N}$ and CEM II/B-V 32.5 R were investigated. For the study on concrete, only CEM 1, CEM 3, CEM 6 and CEM 10 cements, which are circled in Fig. 1 and Fig. 2, have been used.

These SCMs have been characterized at the chemical and mineralogical levels and they meet the requirements from standard EN 197-1 regarding the properties of the cement constituents. Then the physical, chemical and mechanical properties of these ternary cements were determined. Nearly all the ternary cements meet the requirements from standard EN 197-1 regarding compressive strength, initial setting time and soundness. In series 1 (OPC-S-L cements), all the 12 cements reach a strength class of minimum $32.5 \mathrm{R}$ and even $52.5 \mathrm{~N}$ for cement containing $65 \%$ of OPC, 30\% of slag and $5 \%$ of limestone filler (CEM 1). In series 2 (OPC-FA-L cements), the compressive strengths obtained are lower than in series 1 , as 8 out of 12 cements reach a strength class of minimum $32.5 \mathrm{~N}$. When the OPC content is less than $50 \%$, the composite cements do not reach a strength class (CEM 3, CEM 7, CEM 11 and CEM 12).

Two types of concrete with a water-to-cement ratio $(\mathrm{w} / \mathrm{c})$ of 0.45 and 0.55 and a cement content of $340 \mathrm{~kg} / \mathrm{m}^{3}$ and $300 \mathrm{~kg} / \mathrm{m}^{3}$ respectively have been made. Sea sand and rolled sand for the fine aggregates as well as crushed limestone for the coarse aggregates with a maximum nominal size of 20 $\mathrm{mm}$ have been used. The grading curve follows the limits specified in standard EN 480-1. A polycarboxylic-ether (PCE) superplasticiser has been used. After a conservation during $24 \mathrm{~h}$ at a temperature of $20 \pm 2^{\circ} \mathrm{C}$, the specimens are removed and placed in water at the same temperature for curing during a variable period depending on the test. For the durability tests, a period of $91 \mathrm{~d}$ has been chosen to provide ideal hydration conditions for these composite cements. As highlighted by several authors, a good curing is important for these blended cements [19-22]. To evaluate the influence of this parameter, a non-ideal curing of $28 \mathrm{~d}$ in 
a climatic chamber at $20^{\circ} \mathrm{C}$ and $60 \%$ of relative humidity has also been applied to some compositions.

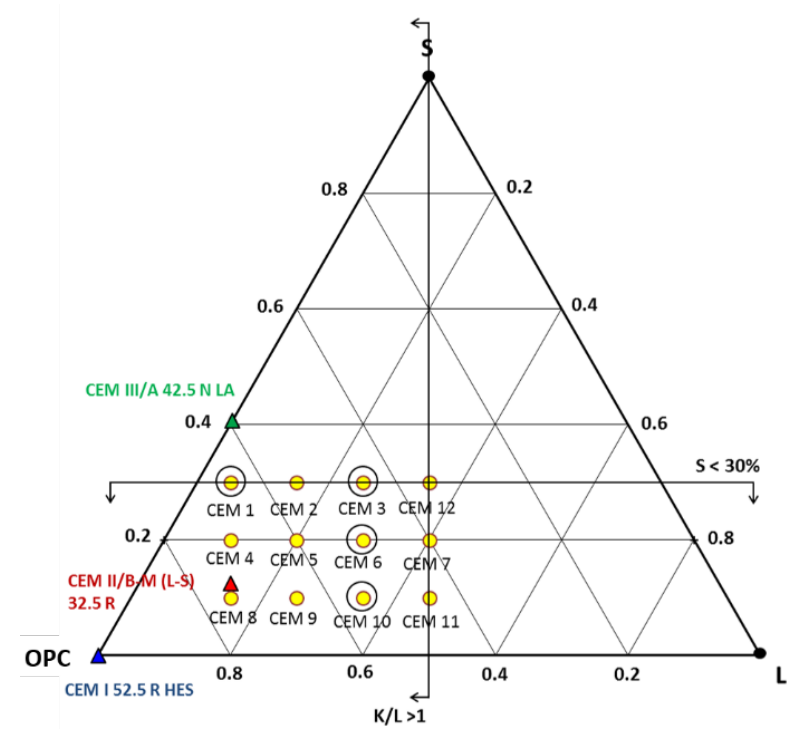

Figure 1. Ternary cements OPC-S-L (series 1 ).

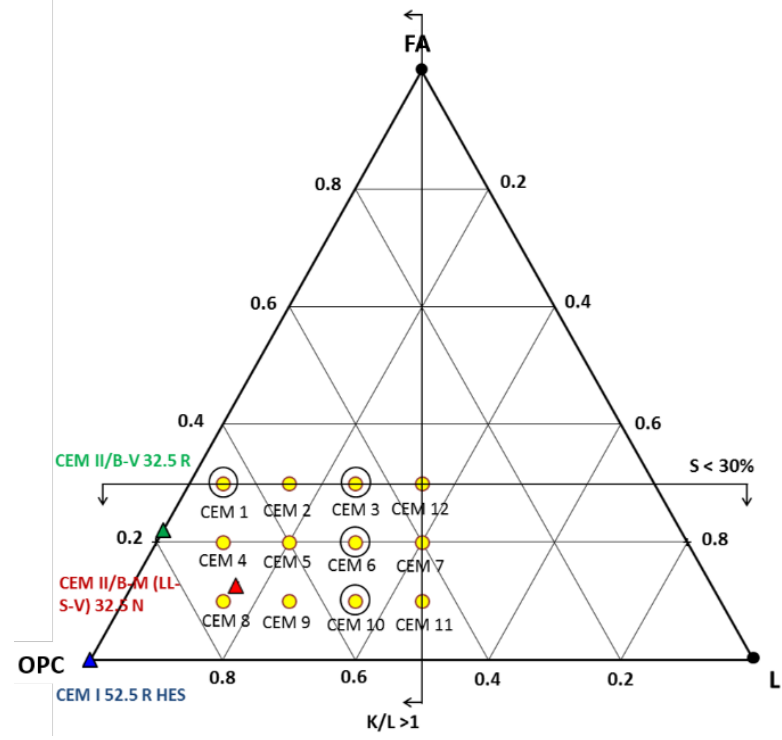

Figure 2. Ternary cements OPC-FA-L (series 2).

\section{Effects of ternary cements on concrete}

When developing new cements, the assessment of their effects on concrete is imperative. A large testing programme (mechanical and durability properties) has been carried out to better understand the behaviour of these ternary cements in concrete. This paper presents the compressive strength, modulus of elasticity and creep briefly, in order to evaluate their predictability according to standard calculation rules (Eurocode 2). Resistance to carbonation and freezing-thawing, chloride diffusion and sulfate attack were also determined to assess their suitability in exposed environments.

First, it has been found that the dosages of admixture for concretes are not excessive and stay in the same range of dosages for the reference concretes as well as in the recommended range of the manufacturer. The dosage for OPC-S-L cements ranges from 0.2 to $0.4 \%$ (by mass of cement), while it ranges from 0.6 to $1.2 \%$ for OPC-FA-L cements. This trend has also been found by Alonso et al. [23]. They found that slag adsorbs less admixture and requires less PCE than fly ash to establish inter-particle repulsion.

Concerning the compressive strength at $28 \mathrm{~d}$ on cubes of 15 $\mathrm{cm}$ side, a concrete with $\mathrm{w} / \mathrm{c}$ of 0.45 made with cement containing $50 \%$ of OPC, $20 \%$ of S and $30 \%$ of L (CEM 6), can reach a compressive strength of $49 \mathrm{MPa}$. The concrete made with a cement of the same proportions but with FA reaches a compressive strength of $36 \mathrm{MPa}$. The compressive strength is mainly influenced by the clinker content. The strengths obtained with OPC-S-L cements are all higher than the ones obtained with OPC-FA-L cements, as seen in Fig. 3. This has also been observed previously because slag is not only pozzolanic but also hydraulic [10, 24]. This additional reactivity gives thus a less porous concrete than with fly ash. In series 1 (OPC-S-L), only concrete made with $65 \%$ of OPC, $30 \%$ of $S$ and $5 \%$ of $L$ (CEM 1 ) has a strength similar to reference concrete made with CEM III/A $42.5 \mathrm{~N}$ LA. In series 2 (OPC-FA-L), when limestone filler is limited to $5 \%$ (CEM 1), the strength is superior to reference concrete made with CEM II/B-V 32.5 R. The compressive strengths measured at $91 \mathrm{~d}$ show the same trends. The synergetic action between the three components (OPC with S or FA and L) seems thus not effective for the mechanical strength when the limestone filler content is high ( $\geq 25 \%$ ).

The results of modulus of elasticity and creep are for most cements respectively superior and inferior to the predicted moduli of elasticity and creep from Eurocode 2 (see [16]). This could be problematic for some applications like industrial floors where shrinkage is restrained. The developed stress could be more important because of a higher modulus of elasticity or a lower creep.

It is known that concrete containing blended cements with slag or fly ash have a less resistance to carbonation than Portland cement. In the atmosphere, carbon dioxide reacts with cement hydration products such as portlandite $\mathrm{Ca}(\mathrm{OH})_{2}$, which buffers the $\mathrm{pH}$. Due to their pozzolanic reactivity, slag and fly ash react with $\mathrm{Ca}(\mathrm{OH})_{2}$ to form $\mathrm{C}-\mathrm{S}-\mathrm{H}$. This reaction as well as the lower content of clinker in blended cements reduce significantly the quantity of portlandite and hence the resistance to carbonation $[13,20,22]$.

The measured resistance to carbonation is thus proportional to the clinker content and to the compressive strength. Compared to reference concrete with CEM I 52.5 R HES (w/c of 0.55 ), concrete with cement containing $50 \%$ of OPC, $20 \%$ of slag and $30 \%$ of $L$ (CEM 6 ), has a carbonation coefficient increased by $55 \%$. Concretes from series 1 (OPC-S-L) show a higher resistance to carbonation than those from series 2 (OPC-FA-L), as shown in Fig. 4. Concrete with fly ash-based cement containing $50 \%$ of OPC, $20 \%$ of FA and $30 \%$ of $\mathrm{L}$ (CEM 6) shows a carbonation coefficient increased by $47 \%$ compared to slag-based cement CEM 6, while the compressive strength at $28 \mathrm{~d}$ is reduced by $34 \%$. 
Curing seems to be a significant parameter to carbonation resistance for concretes with composite cements as well as for reference concretes.

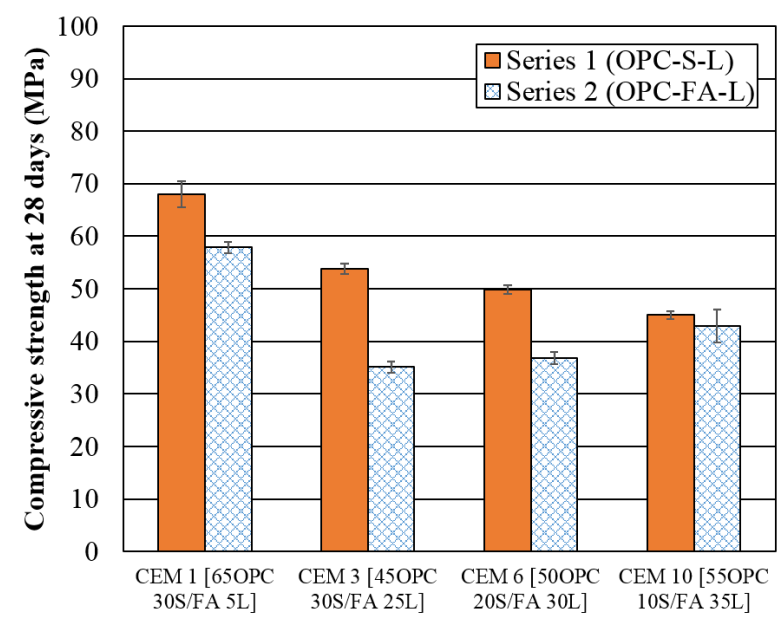

Figure 3. Compressive strength at $28 \mathrm{~d}$ for concretes with $w / c$ of 0.45 .

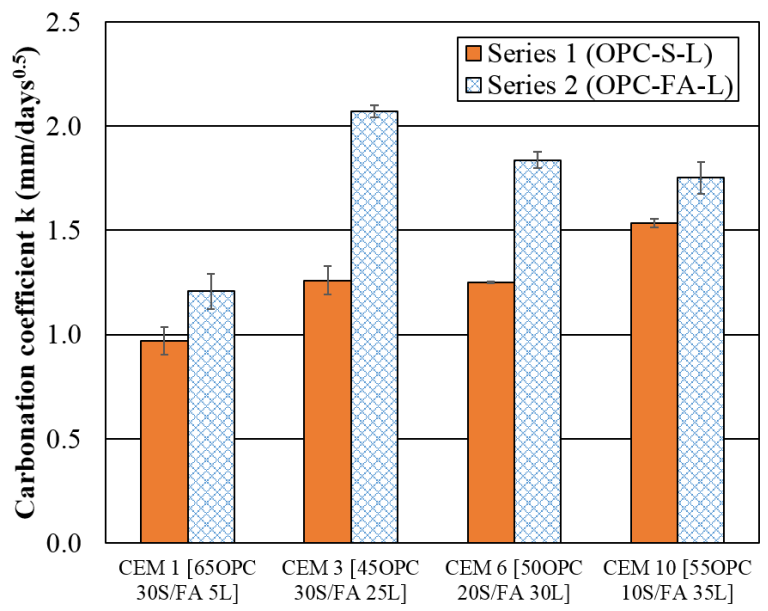

Figure 4. Carbonation coefficients for concretes with w/c of 0.55 .

The carbonation depth after $56 \mathrm{~d}$ of exposition to $1 \%$ of $\mathrm{CO}_{2}$ increases by $35 \%$ for concrete made with CEM 6 which has been subjected to the non-ideal curing.

The resistance of blended cements to frost with de-icing salts has not been thoroughly investigated yet [19]. The measured cumulated loss materials are more important for concretes made with ternary cements than for reference concretes. It seems that the scaling resistance is reduced with increasing limestone filler content. Concrete made with a cement containing 65\% OPC, 30\%FA and 5\% (CEM 1) presents a better resistance than reference concrete made with CEM II/B-M (LL-S-V) $32.5 \mathrm{~N}$, which contains $13 \%$ of limestone filler, $9 \%$ of fly ash and $7 \%$ of slag. In composite cements with fly ash and at least $25 \%$ of limestone filler, the cumulated loss materials increases by more than $45 \%$ compared to CEM II/B-M (LL-S-V) $32.5 \mathrm{~N}$. The resistance to frost is also strongly influenced by the curing. Reference concrete made with CEM I 52.5 R HES has a reduced resistance by $60 \%$ when subjected to the non-ideal curing.
An adequate entrained air void system could also prevent such freezing and thawing attack $[20,22,25]$.

Concerning the resistance to chloride penetration, the presence of blast furnace slag and fly ash seems to be positive. The diffusion coefficients of concretes with most composite cements are inferior or equal to those of references, except for concrete with $35 \%$ of limestone filler (CEM 10). Compared to clinker, slag seems to have a higher chloride binding capacity [26]. The C-S-H produced by the pozzalonic reaction of slag have also a higher chloride adsorption [20,25]. The higher chloride binding capacity of fly ash has also been observed [27]. Blended cements are more sensitive to the curing that reference cements. The non-ideal curing is unfavourable to the pozzolanic reaction of slag and fly ash.

Blast furnace slag and fly ash are also positive for mitigating expansions due to sulfate attack. This is due to lower content of tricalcium aluminate $C_{3} A$, which is the main reactive material $[13,20]$, and due to the low aluminium content of slag $[20,22]$. All ternary cements present a good resistance to sulfate attack (expansion less than $0.02 \%$ ), except for CEM 10 mortar, while mortars made with CEM I 52.5 R HES show the worst performance. Even a mortar made with sulfate resistant cement CEM I 52.5 R LA - SR 3 presents an expansion of about $1 \%$ after one year. Hossack and Thomas found that the intensity of ettringite peaks was greater in mortar bars containing fly ash and limestone filler than mortar bars containing slag and limestone filler, which may indicate a lower permeability and thus a less resistance to sulfate for slag cement [28]. When comparing the two series, it seems indeed that fly ash is even more favourable to mitigate the sulfate attack. For more detailed results on the durability properties, see [17].

The environmental impact of concrete made with these new ternary cements has not been assessed, though performing a life cycle assessment (LCA) is necessary to fully evaluate the potential of these "eco-cements". The LCA is considered as a reliable tool but small variances in the choices of the parameters may induce important differences in the final result [29]. Chen et al. [30] pointed out the question of allocation and Van den Heede and De Belie [29] recommend an economic allocation for SCMs to insure their environmental benefit. Damineli et al. [31] defined a binder intensity index bi and $\mathrm{CO}_{2}$ intensity index ci to measure the eco-efficiency of cement use. High rate of clinker substitution is related to low ci values but high $b i$ values, which could lead to a rapid depletion of conventional SCMs like fly ash.

\section{$4 \quad$ Recommendations and conclusions}

As indicated in the Cement Roadmap, besides the regional availability of the substitution materials, there are other nontechnical barriers such as the national standards for composite cements and the common practice and acceptance of the composite cements by construction contractors and customers. Clinker substitution is a good solution to reduce the environmental impact of the 
construction industry and is commonly used nowadays. To even better stimulate the use of these composite cements and to remove these barriers, it is necessary to assess their suitability for use for concrete.

Despite the fact that ternary cements meet the requirements of European standard EN 197-1, these cements could not be used in concrete in all applications. For the tests conditions and materials of this research, it has been observed that concretes made with new ternary cements, up to $30 \%$ of limestone filler and $20 \%$ of slag or fly ash, show a good performance regarding resistance to chloride diffusion and to sulfate attack. For carbonation and freeze-thaw tests, as well as for compressive strength, it seems that especially the presence of limestone filler is negative, when the content is superior to $25 \%$. Besides, it has been seen that predictive models from Eurocode 2 may not be suitable for most of the tested composite cements. There are some cases for which these poor predictions could have an impact in terms of underutilization of the performance of the material depending on the applications. An adjustment of the concrete mix (cement content, w/c, grading curve, air entraining agent...) or special precautions (thicker covering...) shall be necessary to use these ternary cements in specific environments and applications or to reach a higher performance. As seen, curing is an important parameter for these cementitious materials. A long curing period is highly recommended for these composite cements. This research concerns conventional supplementary cementitious materials but there is a need nowadays to investigate more and more alternative sources of SCMs.

\section{Acknowledgements}

The authors would like to thank the Wallonia Government for the financial support (grants 1017127 and 1217819) as well as the National Centre for Scientific and Technical Research for the Cement Industry for the production and characterization of the ternary cements.

\section{References}

[1] European Commission, Communication from the Commission to the Europe Parliament, the Council, the European Economic and Social Committee and the Committee of the Regions - A Roadmap for moving to a competitive low carbon economy in 2050, Brussels, 2011.

[2] C. Meyer, The greening of the concrete industry, Cem Concr Compos (2009) 31: 601 - 605. https://doi.org/10.1016/j.cemconcomp.2008.12.010

[3] J. Damtoft, J. Lukasik, D. Herfort, D. Sorrentino, E. Gartner, Sustainable development and climate change initiatives, Cem Concr Res (2008) 38(2): 115-127. https://doi.org/10.1016/j.cemconres.2007.09.008

[4] International Energy Agency and Wolrd Business Council for Sustainable Development, Cement Technology Roadmap 2009 Carbon emissions reductions up to 2050, 2009.

[5] CEMBUREAU, 3rd International Symposium "Sustainability in Cement and Concrete", Brussels, 2007.

[6] FEBELCEM, "Rapport annuel de l'industrie cimentière belge," FEBELCEM, Brussels, 2015.

[7] K. De Weerdt, K. O. Kjellsen, E. J. Sellevold, H. Justnes, Synergy between fly ash and limestone powder in ternary cements, Cem Concr Compos (2011) 33(1): 30 - 38.

https://doi.org/10.1016/j.cemconcomp.2010.09.006
[8] R. Snellings, Assessing, Understanding and Unlocking Supplementary Cementitious Materials, RILEM Tech Lett (2016) 1: 50-55. https://doi.org/10.21809/rilemtechlett.2016.12

[9] M. Antoni, J. Rossen, F. Martirena, K. Scrivener, Cement substitution by a combination of metakaolin and limestone, Cem Concr Res (2012) 42: 1579-1589. https://doi.org/10.1016/j.cemconres.2012.09.006

[10] M. C. Alonso, J. L. Garcia Calvo, M. Sanchez, A. Fernandez, Ternary mixes with high mineral additions contents and corrosion related properties, Mater Corrosion (2012) 63(12): 1078 - 1086. https://doi.org/10.1002/maco.201206654

[11] P. Mounanga, M. Irfan Ahmad Khokhar, R. El Hachem, A. Loukili, Improvement of the early-age reactivity of fly ash and blast furnace slag cementitious systems using limestone filler, Mater Struct (2011) 44: 437 - 453. https://doi.org/10.1617/s11527-010-9637-1

[12] G. Menéndez, V. Bonavetti, E. F. Irassar, Strength development of ternary blended cement with limestone filler and blast-furnace slag, Cem Concr Compos (2003) 25: 61 - 67. https://doi.org/10.1016/S0958-9465(01)00056-7

[13] L. Courard, F. Michel, Limestone fillers cement based composites : effects of blast furnace slags on fresh and hardened properties, Constr Build Mater (2014) 51: 439 - 445. https://doi.org/10.1016/j.conbuildmat.2013.10.076

[14] K. De Weerdt, M. Ben Haha, G. Le Saout, K. Kjellsen, H. Justnes, B. Lothenbach, Hydration mechanisms of ternary Portland cements containing limestone powder and fly ash, Cem Concr Res (2011) 41: 279-291. https://doi.org/10.1016/j.cemconres.2010.11.014

[15] H. S. Mueller, M. Haist, J. S. Moffatt, M. Vogel, Environmental impact, performance and service lifetime - Pillars of sustainable concrete construction, Second International Conference on Concrete Sustainability, Madrid, 2016.

[16] K.-S. Lauch, V. Dieryck, B. Parmentier, Fresh and mechanical properties of concrete made with ternary cements containing slag or fly ash and limestone filler, International RILEM Conference on Materials, Systems and Structures in Civil Engineering, Lyngby, 2016.

[17] K.-S. Lauch, V. Dieryck, Durability of concrete made with ternary cements containing slag or fly ash and limestone filler, International RILEM Conference on Materials, Systems and Structures in Civil Engineering, Lyngby, 2016.

[18] J. Piérard, F. Michel, Fillers calcaires : quel avenir dans les bétons, CSTC-Contact, Brussels, 2008.

[19] S. E. Chidiac, D. K. Panesar, Evolution of mechanical properties of concrete containing ground granulated blast furnace slag and effects on the scaling resistance test at 28 days, Cem Concr Compos (2008) 30: 63-71. https://doi.org/10.1016/j.cemconcomp.2007.09.003

[20] R. D. Hooton, Canadian use of ground granulated blast-furnace slag as a supplementary cementing material for enhanced performance of concrete, Canadian J Civ Eng (2000) 27: 754 - 760. https://doi.org/10.1139/100-014

[21] P. K. Mehta, High-performance, high-volume fly ash concrete for sustainable development, Proceedings of the international workshop on sustainable development and concrete technology. Ames, IA, USA, 2004.

[22] G. J. Osborne, Durability of Portland blast-furnace slag cement concrete, Cem Concr Compos (1999) 21: 11-21. https://doi.org/10.1016/S0958-9465(98)00032-8

[23] M. M. Alonso, M. Palacios, F. Puertas, Compatibility between polycarboxylate-based admixtures and blended-cement pastes, Cem Concr Compos (2013) 35: 151 - 162 https://doi.org/10.1016/j.cemconcomp.2012.08.020

[24] W. M. Hale, S. F. Freyne, T. D. Bush Jr., B. W. Russell, Properties of concrete mixtures containing slag cement and fly ash for use in transportation structures, Constr Build Mater (2008) 22: 1990 2000. https://doi.org/10.1016/j.conbuildmat.2007.07.004

[25] J. Geiseler, H. Kollo, E. Lang, Influence of blast furnace cements on durability of concrete structures, ACI Mater J (1995) 92(3): 252 - 257.

[26] O. Kayali, M. S. H. Khan, M. Sharfuddin Ahmed, The role of hydrotalcite in chloride binding and corrosion protection in concretes with ground granulated blast furnace slag, Cem Concr Compos (2012) 34: 936 - 945. https://doi.org/10.1016/i.cemconcomp.2012.04.009

[27] S. G. Ytterdal, The effect of fly ash and ggbfs as cement replacement on chloride binding and ingress in mortar samples, NTNU, Trondheim, 2014

[28] A. M. Hossack, M. D. A. Thomas, Varying fly ash and slag contents in Portland limestone cement mortars exposed to external sulfates, Constr Build Mater (2015) 78: 333 - 341. https://doi.org/10.1016/j.conbuildmat.2015.01.030 
[29] P. Van den Heede, N. De Belie, Environmental impact and life cycle assessment (LCA) of traditional and 'green' concretes: Literature review and theoretical calculations, Cem Concr Compos (2012) 34: 431-442. https://doi.org/10.1016/j.cemconcomp.2012.01.004

[30] C. Chen, G. Habert, Y. Bouzidi, A. Jullien and A. Ventura, "LCA allocation procedure used as an incitative method for waste recycling: an application to mineral additions in concrete," Resources, Conservation and Recycling, vol. 54, pp. 1231-1240, 2010. https://doi.org/10.1016/i.resconrec.2010.04.001

[31] B. L. Damineli, F. M. Kemeid, P. S. Aguiar, V. M. John, Measuring the eco-efficiency of cement use, Cem Concr Compos (2010) 32: 555562. https://doi.org/10.1016/j.cemconcomp.2010.07.009 